\title{
What are the patterns of compliance with Early Warning Track and Trigger Tools: A narrative review
}

\section{Credland, Nicola; Dyson, Judith; Johnson, Miriam}

(C) 2018. This manuscript version is made available under the CC-BY-NC-ND 4.0 license http://creativecommons.org/licenses/by-nc-nd/4.0/

Background: Early Warning Scores were introduced into acute hospitals in $2000.99 \%$ of acute hospitals employ a EWS to monitor deteriorating patients with $97.9 \%$ of these linked to a referral protocol. Despite this high level of adoption, there has been little improvement in the recognition and response to deteriorating patients over the last decade.

Objective: To explore the patterns of compliance with Early Warning Track and Trigger Tools

Design: A narrative review

Data sources: Electronic databases (Medline, CIHAHL, EmBase, the Cochrane library, the Centre for Reviews and Dissemination (CRD) and PROSPERO) were searched from 1 January 2000 to 5 July 2018. Titles, abstracts and full text papers were screened (two independent reviewers) against inclusion criteria and seven papers were included in the review. Data were extracted by one reviewer and checked by a second reviewer using a bespoke data collection sheet.

Review methods: All papers were quantitative in design but demonstrated clinical and methodological heterogeneity therefore a meta-analysis was not possible. A qualitative approach was undertaken to synthesise findings using a framework analysis and narrative synthesis. Themes were identified, named, defined and reported according to outcome measure.

Results: 7/27 papers representing over 3000 patients and 963,000 data points were included in the analysis. Reported studies were conducted in the United Kingdom $(n=4)$, Denmark $(n=2)$ and Amsterdam $(n=1)$. Three key themes were identified, early warning score calculation accuracy, monitoring frequency and clinical response. This review identifies poor compliance with the Early Warning Score (EWS) protocol in all three themes. There is significant scoring inaccuracy with omitted EWS, missing elements of the EWS and incorrectly calculated EWS. Adherence to monitoring frequency is poor with a higher EWS being associated with reduced compliance with the escalation protocol. There is inadequate compliance with the escalation element of the EWS protocol with concerning extended 
delays to clinical review. There is evidence of worsening clinical response with increasing EWS. Although significant improvement is demonstrated in clinical response with the use of electronic EWS protocols, non-compliance still occurs at all EWS stages.

Conclusion: Compliance with EWS is poor but the cause is unidentified. Outcomes can only improve if staff complete the EWS fully, calculate the score accurately, monitor according to protocol and escalate according to clinical response. Social, environmental and professional behaviours that affect effective use of track and trigger tools should be explored to improve our understanding of suboptimal management of the deteriorating patient.

\section{What is already known about this topic?}

- Early warning track and trigger tools have been implemented nationally and to a lesser degree internationally

\section{What this paper adds}

- Compliance with EWS is poor and current research fails to identify why this may be the case.

- Outcomes can only be positively affected if staff complete the EWS in its entirety, calculate the score accurately, monitor in line with the protocol frequency and escalate according to clinical response.

- Failure to manage the deteriorating patient could be better understood by exploring the social, environmental and professional behaviours that impact on the effective use of track and trigger tools

\section{Introduction and background}

A review of 1000 medical records of adults who died in 10 acute hospitals across England found that one in twenty patients die as a result of medical error with one death in 20 having a greater than $50 \%$ chance of being preventable and $31 \%$ of preventable deaths being due to poor clinical monitoring (Hogan et al. 2012). There is evidence to suggest that a lack of knowledge and skills, inadequate appreciation of clinical urgency and failure to seek expert 
advice in a timely fashion contributes to inadequate recognition of and response to the deteriorating patient (McQuillan et al. 1998).

Approximately $80 \%$ of hospital in-patients who suffer cardiac arrest show signs and symptoms of deterioration in the hours leading up to the event (Resuscitation Council (UK), 2010; NCEPOD 2012). Failure to recognise physiological deterioration in acutely ill adults, combined with a failure to seek appropriate help promptly and intervene in a timely manner, results in increased rates of cardiac arrest and unanticipated intensive care admissions (Hogan et al. 2012, Franklin and Matthew, 1994; McQuillan et al. 1998; Smith et al. 2006). In such patients' mortality is high, with only $7 \%$ of non-shockable cardiac arrests surviving to discharge (Intensive Care National Audit Research Centre, 2012).

Historically, several key reports highlighted sub-optimal management of patients both discharged from Intensive Care Unit's (ICU) and at risk of deterioration on general wards, with evidence of deficits in their care and management (Goldhill et al. 1999; Mc Gloin et al. 1999; Garrard et al. 1998; Mc Quillan et al. 1998). The reasons for the failure to detect patients at risk of acute deterioration include poor critical care knowledge of ward based medical teams (Franklin and Matthew, 1994; Welsh, 2000; Goldhill, 2000). It is also recognised that lack of resources, increasing volume and acuity of patients can compromise acute care provision compounding failure to detect deterioration (McGloin et al. 1999). Only $2 \%$ of acute hospital beds are designated for critical care (Audit Commission 1999) so the optimisation of ward based patient management requires timely identification and intervention to support deteriorating patients (Welsh, 2000; McGloin et al. 1999). Hogan et al. (2012) suggests that, despite implementation of track and trigger systems, there has been little improvement over the last decade with sub-optimal care still evident on general wards impacting directly on patient outcome.

Early Warning Scores (EWS) with an associated escalation strategy (often referred to as track and trigger systems) were first introduced into acute hospitals in 2000 (Department of Health (DoH) 2000a). Ninety nine percent of acute hospitals employ a EWS to monitor deteriorating patients with $97.9 \%$ of these linked to a referral protocol (NCEPOD, 2015). Despite this high level of adoption, there has been little improvement in the recognition and response to deteriorating patients over the last decade. Sub-optimal care is still evident on general wards despite the comprehensive introduction of EWS and escalation strategies (Hogan et al. 2012).

This review aimed to examine international research relating to the relationship between early warning track and trigger tools and compliance. The research question guiding the review was: 
What are the patterns of compliance with Early Warning Track and Trigger Tools?

\section{Methods}

The review protocol was registered on Prospero (CRD42017074401) (PROSPERO, 2014). The search methods employed for this review are adapted from the Cochrane Handbook of Systematic Reviews (Higgins and Green, 2011) and reported according to the Preferred Reporting Items for Systematic Reviews and Meta-Analyses (PRISMA) Statement (Moher et al., 2015).

\subsection{Selection Criteria}

\subsubsection{Inclusion and Exclusion Criteria}

The Population, Intervention, Comparison, Outcome (PICO) acronym (O'Conner et al. 2008) was used to develop inclusion and exclusion criteria (table 1). An inclusive approach was used as there is a dearth of evidence and it was important to capture all the relevant research available that answered the research question.

Table 1. Eligibility criteria

\begin{tabular}{|c|c|}
\hline Popu & $\begin{array}{l}\text { Included } \\
\text { - } \quad \text { Adult patients not managed in critical care areas (intensive care and } \\
\text { high dependency) } \\
\text { Excluded } \\
\text { - Patients managed in critical care areas (intensive care and high } \\
\text { - } \text { dependency) } \\
\text { - Obediatric track and trigger tool research } \\
\text { Obstetric track and trigger tool research }\end{array}$ \\
\hline Intervention & $\begin{array}{l}\text { Included } \\
\text { - Aggregate weighted track and trigger systems } \\
\text { - Primary empirical, peer reviewed research including systematic } \\
\text { reviews, RCT's, cohort and case controlled studies and cross- } \\
\text { sectional surveys. } \\
\text { Excluded } \\
\text { - Opinion papers, case reports and papers using a qualitative } \\
\text { methodology } \\
\text { - Single parameter systems }\end{array}$ \\
\hline Outcome & $\begin{array}{l}\text { Included } \\
\text { - Studies which presented quantitative date measuring compliance } \\
\text { with early warning scoring systems } \\
\text { Excluded } \\
\text { - Studies with no compliance outcome measures } \\
\text { - Studies that explored qualitative aspects of compliance with track and } \\
\quad \text { trigger systems }\end{array}$ \\
\hline
\end{tabular}




\subsection{Search strategy}

Data bases searched were Medline, CIHAHL and the Cochrane library. Population (i.e. adult patients only) was not used as a search term but non-adult studies filtered during the screening process. As Early Warning Scores were only introduced in 2000 this date was used to limit the search. Citation searching, searches of reference lists for missed studies and 'find similar' options in other databases such as 'Scopus' and 'Web of Science' along with a search of Google Scholar were also conducted to identify missed, non-indexed and unpublished material. Studies known to the researcher prior to the search were used for cross-checking to ensure that the search strategy had not missed these studies. A search of the grey literature (government reports, non-published literature) was also undertaken. Relevant Government and clinical reports have been discussed previously and no further studies were identified. A preliminary scoping review was used to identify the full spectrum of search terms. These were "track and trigger" OR "early warning scor" and "complian*". A librarian checked the strategy to ensure a robust search.

\subsection{Study selection}

After removal of duplicates, titles and abstracts were independently screened by NC and JD against the inclusion and exclusion criteria. Full texts were similarly reviewed. MJ was available to support resolution of any disagreements in whether papers were appropriate for inclusion however, in all cases agreement was achieved.

\subsection{Quality assessment}

Critical Appraisal Skills Programme (CASP) Critical Appraisal tools were used to assess the quality of the included papers (CASP, 2014). Numerical scores were derived by attributing 1 mark for a yes answer and 0 marks for a no / don't know answer.

\subsection{Data extraction}

The data extracted included publication details, study designs, participants, interventions, outcomes and results. Data were extracted by NC and independently reviewed by JD. MJ was available to support resolution of any disagreements however, in all cases agreement was achieved.

\subsection{Data synthesis}


Due to heterogeneity with regard to population and design it was not possible to carry out a meta-analysis. This review identified clinical heterogeneity (the patients are not the same) and methodological heterogeneity (all the studies were not conducted in the same manner). A qualitative approach was undertaken to synthesise findings using a framework analysis (Miles and Huberman, 1994) and narrative synthesis (Ferrari, 2015) with results analysed based on outcome. A framework analysis facilitates the generation of a set of codes organised into categories to manage and organise data. These codes are grouped into clusters around similar and interrelated ideas and concepts. The author explored the familiarisation of included papers and their findings. The papers were re-read several times to ensure understanding. Each paper was marked with highlighters allocated to different emerging patterns/codes. The results of each paper were considered in relation to the research question. The patterns identified led the formation of themes using a white board. Themes were arranged into logical groups which directly addressed the research question. This process was repeated to ensure no relevant data had been missed and that the themes chosen were coherent and answered the research question. The themes were identified, named, defined and reported according to outcome measure and analysed in relation to the research question. A narrative synthesis refers to an approach to the systematic review and synthesis of findings from multiple studies that relies primarily on the use of words and text to summarise and explain the findings of the synthesis. The practical-configurational mode of reasoning in narrative synthesis focuses on making sense of the reading of the evidence 'what is going on here?' or 'what picture emerges?' (Melendez- Torres et al. 2016).

\subsection{Results}

\subsection{Study selection}

Of the 27 titles found by the search, seven papers representing over 3000 patients and 963,000 data points were included in the analysis. Reviews and Meta-Analysis diagram (PRISMA) (Moher et al. 2015) detailing the process of inclusion and exclusion is provided in Figure 1. 
Figure 1: PRISMA diagram

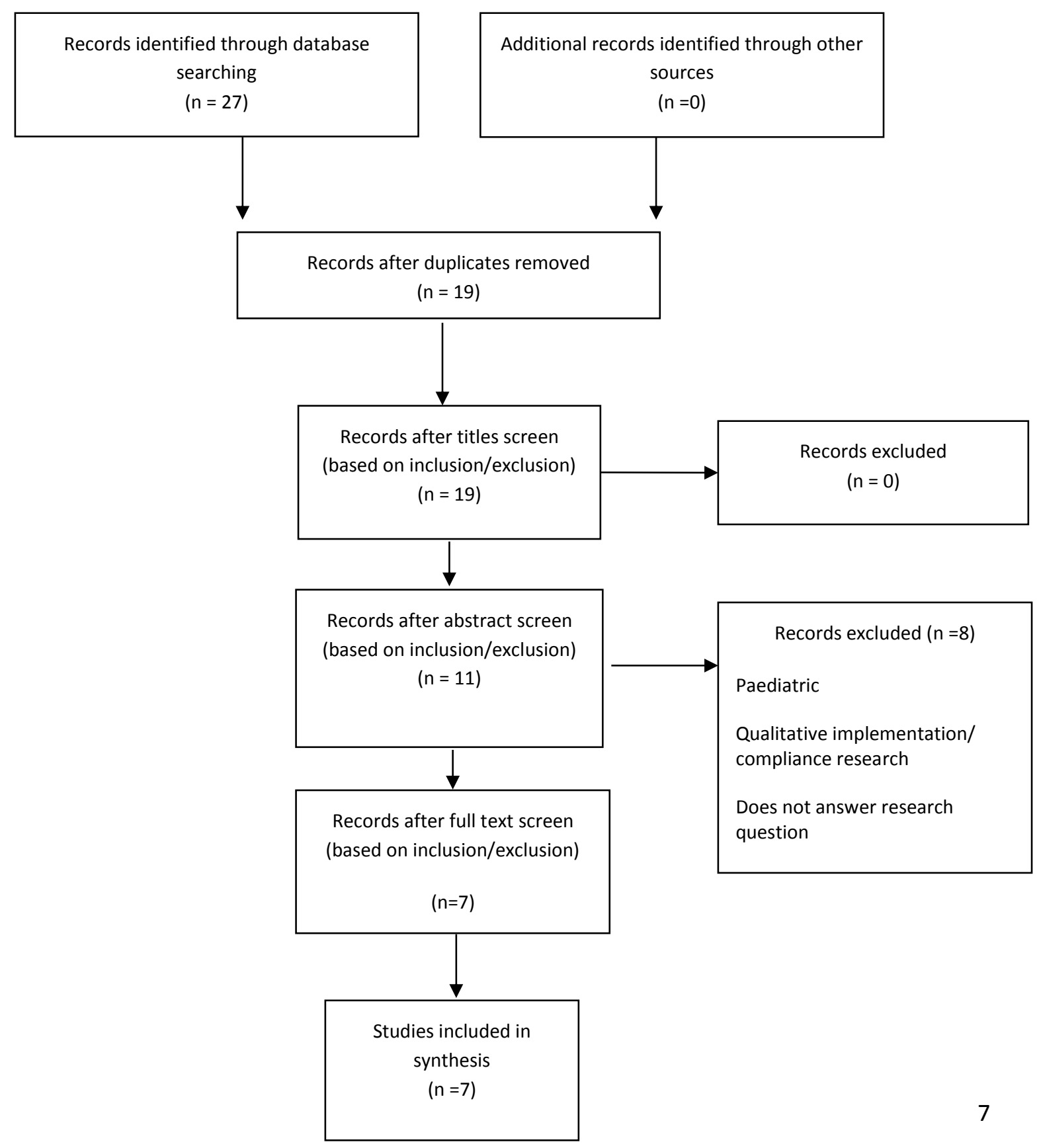




\subsection{Study characteristics}

\subsubsection{Study designs}

All included papers were of quantitative design and were published between 2013 and 2016 in English. Data were collected using either a case note review / notes audit, prospective observational design, a point prevalence design or a quasi-experimental approach. Settings were all in acute hospital general wards. The seven papers reported studies conducted in 3 European countries; the United Kingdom ( $n=4)$, Denmark $(n=2)$ and Amsterdam $(n=1)$ emphasising the increasing international interest in the subject. A summary of included papers can be found in Figure 2. 
Figure 2: Summary of Studies included in the review

\begin{tabular}{|c|c|c|c|c|c|c|}
\hline Study & Design & Sample & Intervention & Outcome measures & Key findings & $\begin{array}{l}\text { Appraisal } \\
\text { rating }\end{array}$ \\
\hline $\begin{array}{l}\text { Jones et } \\
\text { al. } \\
(2011) \\
\text { UK }\end{array}$ & $\begin{array}{l}\text { Historically } \\
\text { controlled study. }\end{array}$ & $\begin{array}{l}\text { University teaching } \\
\text { hospital } \\
\text { Medical admissions unit } \\
\text { and one general medical } \\
\text { ward } \\
1481 \text { consecutive adult } \\
\text { patients generating } 13,668 \\
\text { data sets }\end{array}$ & $\begin{array}{l}\text { Implementation of } \\
\text { patient track } \\
\text { based on EWS } \\
\text { protocol in place } \\
\text { since } 2000\end{array}$ & $\begin{array}{l}\text { PO- Length of stay } \\
\text { SO- Compliance with } \\
\text { EWS } \\
\text { Cardiac arrest incidence } \\
\text { In hospital mortality } \\
\text { Use of critical care beds }\end{array}$ & $\begin{array}{l}\text { EWS calculated correctly in } 81 \% \text { of cases. } \\
\text { Non-compliance of } 9-10 \% \text { with timeliness of observation } \\
\text { re-check } \\
\text { Complete compliance with the EWS protocol including } \\
\text { timeliness of clinical response could not be accurately } \\
\text { determined due to poor documentation of attendance } \\
\text { times in medical records }\end{array}$ & $\begin{array}{l}\text { CASP } \\
12 / 13\end{array}$ \\
\hline $\begin{array}{l}\text { Hands et } \\
\text { al. } \\
(2013) \\
\text { UK }\end{array}$ & $\begin{array}{l}\text { Retrospective data } \\
\text { set audit }\end{array}$ & $\begin{array}{l}\text { NHS District General } \\
\text { Hospital } \\
\text { All adult in-patient areas } \\
950043 \text { vital sign data sets }\end{array}$ & $\begin{array}{l}\text { EWS using } \\
\text { VitalPac electronic } \\
\text { vital sign } \\
\text { recording }\end{array}$ & $\begin{array}{l}\text { Hourly and daily patterns } \\
\text { of vital signs } \\
\text { ViEWS value } \\
\text { documentation } \\
\text { No of vital signs } \\
\text { recorded between } 08: 00- \\
11: 59 \text { with time to next } \\
\text { observation and follow up } \\
\text { vital signs in } 6 \mathrm{hrs}\end{array}$ & $\begin{array}{l}\text { At best partial adherence to EWS protocol } \\
\text { Sicker patients more likely to have overnight } \\
\text { observations but timely reassessment of these patients } \\
\text { remains poor. } \\
\text { Lack of compliance uniformity over the } 24 \mathrm{hr} \text { period }\end{array}$ & $\begin{array}{l}\text { CASP } \\
13 / 13\end{array}$ \\
\hline $\begin{array}{l}\text { Niegsch } \\
\text { et al. } \\
(2013) \\
\text { Denmark }\end{array}$ & $\begin{array}{l}7 \text { day prospective, } \\
\text { observational, } \\
\text { randomised, cross- } \\
\text { sectional, point } \\
\text { prevalence study }\end{array}$ & $\begin{array}{l}\text { In-hospital patients on } 12 \\
\text { medical and surgical wards } \\
n=132\end{array}$ & $\begin{array}{l}\text { Calculation of } \\
\text { EWS by } \\
\text { investigator } \\
\text { between 16:00 and } \\
21: 00 \text { each day. } \\
\text { Structured } \\
\text { questionnaire to } \\
\text { interview ward } \\
\text { nurse if abnormal } \\
\text { EWS identified } \\
\text { Comparison with } \\
\text { investigator and } \\
\text { staff EWS }\end{array}$ & $\begin{array}{l}\text { Number of in-hospital } \\
\text { patients observed and } \\
\text { managed according to } \\
\text { the Ward Observational } \\
\text { Chart (EWS) guidance }\end{array}$ & $\begin{array}{l}\text { Low compliance with the Ward Observational Chart } \\
58 \% \text { managed correctly according to the EWS protocol. } \\
\text { No significant difference between department or day of } \\
\text { the week. } 12 \text { patients had missing physiological } \\
\text { parameters despite a EWS calculation. } 50 \text { patients had } \\
\text { abnormal EWS recorded but of these only } 38 \% \text { were } \\
\text { correctly escalated. } \\
73 \text { patients had abnormal EWS identified by the } \\
\text { investigator but only known by staff in } 60 \% \text { of cases. }\end{array}$ & $\begin{array}{l}\text { CASP } \\
11 / 13\end{array}$ \\
\hline $\begin{array}{l}\text { Ludikhui } \\
\text { ze et al. } \\
(2014) \\
\text { Amsterd } \\
\text { am }\end{array}$ & $\begin{array}{l}\text { Quasi-experimental } \\
\text { study }\end{array}$ & $\begin{array}{l}\text { University hospital } \\
18 \text { adult general wards } \\
\mathrm{n}=804\end{array}$ & $\begin{array}{l}\text { Protocolised group } \\
(10 \text { wards) }=\text { vital } \\
\text { signs } \times 3 \text { times per } \\
\text { day } \\
\text { Control group ( } 8 \\
\text { wards) = vital } \\
\text { signs when } \\
\text { clinically indicated }\end{array}$ & $\begin{array}{l}\text { Compliance with set } \\
\text { monitoring standards } \\
\text { including EWS } \\
\text { Delay in escalation to } \\
\text { physician } \\
\text { Rapid response team } \\
\text { activation }\end{array}$ & $\begin{array}{l}\text { EWS in } 70 \% \text { of patients on the protocolised wars } \vee 2 \% \text { in } \\
\text { the control group. Compliance with the protocol present } \\
\text { in } 68 \% \text { of cases } v 4 \% \text { in the control group. Increased } \\
\text { escalation present in the protocolised group }\end{array}$ & $\begin{array}{l}\text { CASP } \\
11 / 13\end{array}$ \\
\hline $\begin{array}{l}\text { Odell M } \\
(2015)\end{array}$ & $\begin{array}{l}\text { Retrospective case } \\
\text { note review }\end{array}$ & $\begin{array}{l}\text { In hospital adult patients } \\
\text { on } 26 \text { general wards }\end{array}$ & $\begin{array}{l}\text { Retrospective } \\
\text { case note review }\end{array}$ & $\begin{array}{l}\text { Compliance with EWS } \\
\text { protocol }\end{array}$ & $\begin{array}{l}20.3 \% \text { of cases scored the maximum for adherence to } \\
\text { EWS protocol. } 50.4 \% \text { failed to reach the minimum }\end{array}$ & $\begin{array}{l}\text { CASP } \\
12 / 13\end{array}$ \\
\hline
\end{tabular}




\begin{tabular}{|c|c|c|c|c|c|c|}
\hline UK & & $\mathrm{n}=120$ & $\begin{array}{l}\text { using predesigned } \\
\text { data collection pro } \\
\text { forma }\end{array}$ & Recording of vital signs & $\begin{array}{l}\text { standard of practice. } 24.3 \% \text { of EWS calculated were } \\
\text { scored incorrectly }\end{array}$ & \\
\hline $\begin{array}{l}\text { Petersen } \\
\text { et al. } \\
\text { (2014) } \\
\text { Denmark }\end{array}$ & $\begin{array}{l}\text { Prospective } \\
\text { observational study }\end{array}$ & $\begin{array}{l}\text { In hospital adult patients } \\
\text { on general wards } \\
n=144\end{array}$ & $\begin{array}{l}\text { Case note review } \\
\text { of all incidents of } \\
\text { unexpected death, } \\
\text { cardiac arrest and } \\
\text { unplanned ICU } \\
\text { admission }\end{array}$ & $\begin{array}{l}\text { Compliance with EWS } \\
\text { protocol for the } 24 \text { hrs } \\
\text { preceding cardiac arrest, } \\
\text { unexpected death and } \\
\text { unplanned ICU admission }\end{array}$ & $\begin{array}{l}\text { Poor compliance with EWS } \\
\text { Correct monitoring frequency undertaken in } 27 \% \text { of } \\
\text { cases } \\
\text { Inadequate clinical response to EWS } 2 \text { (58\%) EWS } 3 \\
(55 \%) \text { EWS } 6(29 \%) \text { and EWS } 9(36 \%)\end{array}$ & $\begin{array}{l}\text { CASP } \\
12 / 13\end{array}$ \\
\hline $\begin{array}{l}\text { Kolic et } \\
\text { al. } \\
(2015) \\
\text { UK }\end{array}$ & $\begin{array}{l}\text { Prospective } \\
\text { observational study }\end{array}$ & $\begin{array}{l}\text { District General Hospital } \\
\text { Adult patients admitted to } \\
\text { Acute Medical Unit } \\
\mathrm{n}=370\end{array}$ & $\begin{array}{l}\text { Review of clinical } \\
\text { response data } \\
\text { collected for first } \\
24 \mathrm{hrs} \text { of admission }\end{array}$ & $\begin{array}{l}\text { EWS scoring accuracy } \\
\text { Adequacy of clinical } \\
\text { response to EWS }\end{array}$ & $\begin{array}{l}\text { EWS calculated incorrectly in } 18.9 \% \text { of patients } \\
25.9 \% \text { patients had an inadequate clinical response to } \\
\text { their EWS } \\
8 \text { patients }(6 \%) \text { who had an adequate response died } \\
\text { compared to } 6 \text { patients who had an inadequate response }\end{array}$ & $\begin{array}{l}\text { CASP } \\
12 / 13\end{array}$ \\
\hline
\end{tabular}




\subsubsection{Identification of themes}

The development of themes can be found in Table 2 .

\begin{tabular}{|c|c|c|c|}
\hline PAPER & $\begin{array}{l}\text { THEME: } 1 \\
\text { EWS calculation } \\
\text { accuracy }\end{array}$ & $\begin{array}{l}\text { THEME: } 2 \\
\text { Monitoring frequency }\end{array}$ & $\begin{array}{l}\text { THEME:3 } \\
\text { Clinical response }\end{array}$ \\
\hline Jones et al (2011) & $\sqrt{ }$ & $\sqrt{ }$ & $\sqrt{ }$ \\
\hline Hands et al (2013) & & $\sqrt{ }$ & \\
\hline Niegsch et al (2013) & $\sqrt{ }$ & & \\
\hline Ludikhuize et al (2014) & $\sqrt{ }$ & & $\sqrt{ }$ \\
\hline Odell M (2014) & $\sqrt{ }$ & $\sqrt{ }$ & $\sqrt{ }$ \\
\hline Petersen et al (2014) & & $\sqrt{ }$ & $\sqrt{ }$ \\
\hline Kolic et al (2015) & $\sqrt{ }$ & & $\sqrt{ }$ \\
\hline
\end{tabular}

Table 2: Development of themes

Three themes were identified which were reported according to outcome measure. These are Early Warning Score calculation accuracy, monitoring frequency and clinical response (Figure 3).



Figure 3: Identified themes 


\subsection{Theme: Early warning score calculation accuracy}

Four papers report EWS calculation accuracy. There is evidence of inadequate calculation leading to ineffective response to increased scores. The issues of concern with calculation accuracy appear three-fold. Firstly, complete lack of EWS recording. Secondly, incorrect addition of each individual physiological parameter that make up the score. Finally, omission of one or more physiological parameters required to make up the EWS resulting in an incorrect overall calculation.

Odell (2015) identified that an EWS was only recorded in $83.7 \%(n=103)$ of total cardiopulmonary arrest cases $(n=123)$. Of these $24.3 \%(n=25)$ were inaccurate due to incomplete observations, under and over calculation. 15 of these EWS, if calculated correctly, should have generated a clinical response suggesting that calculation inaccuracy leads to suboptimal referral decisions. In total $36.5 \%$ of cases had an ineffective EWS recording leading to poor adherence to the EWS protocol. Niegsch et al. (2013) identified patients with a calculated EWS despite incomplete vital parameters for calculation. In 132 patients only $77 \%$ had a EWS calculated again suggesting poor adherence to the EWS protocol. 12 patients were identified that had a EWS calculated despite one of more missing elements required for calculation. A further 12 patients had all the necessary parameters completed but no EWS calculated. Kolic at al. (2015) also identified EWS scoring errors in $18.9 \%$ of patients $(n=70)$. Interestingly, the study identified a direct correlation between high EWS scores (EWS $>7)$ and a significant increase in scoring error $(p<0.008)$. Patients with high EWS scores are the most critically ill and in need of urgent clinical response. Incorrect EWS scores in this group of patients can lead to cardiac arrest and unexpected death again suggesting that scoring accuracy plays a vital part in patient outcome. Ludikhuize et al. (2014) identified calculation errors in both a EWS protocolised group (measurement of EWS at least three times a day) and a control group (measurement of EWS when clinically appropriate). Missing parameters and errors in calculation accuracy were found to be statistically significant across both groups $(p<0.001)$. Interestingly, in the categories 3 or more errors and 3 or more missing parameters the errors were higher in the control group suggesting that implementing a protocol rather than relying on clinical decision making improves management of the deteriorating patient. However, only $14 \%(483 / 3585)$ of protocol measurements versus $0.3 \%$ (8/3013) of control group measurements were entirely without error which, whilst improvement is noted still demonstrated suboptimal compliance with EWS protocol. Jones et al. (2011) explored whether automated clinical alerts increase compliance with EWS protocol. Scoring accuracy improved from $81 \%$ to $100 \%$ suggesting that human error significantly impacts on EWS compliance. The errors in calculation were overestimates (false positives) and underestimates (false negatives). There were 12 
instances where the underestimated score should have triggered a clinical response if calculated correctly. This highlights the importance of EWS scoring accuracy in compliance with the EWS protocol.

\subsection{Theme: Monitoring frequency}

Four papers explore monitoring frequency. Adherence to EWS monitoring frequency is poor with higher EWS being associated with reduced compliance with the protocol. Compliance with EWS may be reduced at a weekend and during night time hours.

Petersen et al. (2014) explored monitoring frequency in unexpected death, cardiac arrest and unanticipated ICU admission $(n=144)$. Monitoring frequency was completely adhered to in only $13 \%$ and $27 \%$ of unintended ICU admission and cardiac arrest respectively. They identified that a higher EWS was significantly associated with a reduced likelihood of being monitored according to the EWS protocol. The incidence fell from $83 \%$ in patients with EWS $<1$ to $6 \%$ in patients with EWS $>9$ ( $p=0.0002$ for unplanned ICU admission and $p=0.0058$ for cardiac arrest). These patients represent the highest risk group in terms of increased unexpected death and cardiac arrest so this failure to monitor according to protocol suggests suboptimal care which impacts on patient outcome. Hands at el. (2013) conclude that adherence to the hospitals protocol for the frequency of EWS monitoring is only partial at best. There is a striking pattern with the presence of increased peaks in monitoring between 06:00-06:59 and 21:00-21:59. The authors suggest that this is likely to coincide with nursing handover and pre-determined hours when observation rounds will be undertaken. Inpatients with the highest EWS score (>9) time to next observations was $4.22 \mathrm{hrs}$ during the daytime and $5.17 \mathrm{hrs}$ overnight. Whilst the time to next observations did decrease with increasing EWS this was not in line with the hospitals monitoring protocol suggesting inadequate compliance leading to sub-optimal care. They also identify variability in vital sign monitoring over the $24 \mathrm{hr}$ period. Vital signs were measured infrequently between $23: 00 \mathrm{hrs}$ to $05: 59 \mathrm{hrs}$ with only $12.81 \%$ of observations being carried out within this period. The proportion of vital signs undertaken in EWS>9 was greater during this period than for any other EWS score suggesting that the sickest patients are more likely to have their vital signs measured overnight. However, there is a marked contrast in compliance with observation recording when comparing day and night time. Between the hours of 08:00-11:59 $73.10 \%$ have subsequent vital sign recording compared to only $25.32 \%$ during 20:00-23:59. Adherence to EWS protocol was always greater during the day time regardless of EWS score suggesting suboptimal care of patients during night time hours. Odell (2015) found that in patients who had a cardiac arrest at the weekend or bank holiday there was more likely to be poor compliance with the EWS protocol in the hours leading up to their arrest $(p=0.0006)$. Jones et al. (2011) explored whether automated EWS would improve observation frequency. There 
was no difference in recheck time interval in EWS of 3,4 and 5 within one hour. This occurred in $27 \%$ and $22 \%$ of instances for the non-automated and automated groups respectively. There remained a non-compliance rate of $9 \%$ non-automated versus $10 \%$ for the automated EWS group after four hours. This suggests that the use of automated EWS systems alone do not improve observation frequency when compared to a manual EWS protocol.

\subsection{Theme: Clinical response}

Five papers explore clinical response to EWS. There is evidence of inadequate compliance with the escalation element of the EWS protocol and worsening clinical response with increasing EWS. Delay in, or indeed omission of, life-saving treatment can increase mortality, unplanned ICU admission, Cardio-pulmonary arrest, length of stay and serious adverse incidents. Timely intervention in this group of patients is vital to improve patient outcomes.

Odell (2015) identified that $50.4 \%$ of 123 cardiac arrest cases failed to meet minimum standards of practice for EWS compliance. The protocol for referring patients for expert help when the EWS threshold was reached failed to be activated in $39 \%$ of cases. Only $1 / 5$ of patients received the optimum standard outlined by the EWS protocol. In 62 cases, the referral decision was flawed which is of serious concern as these patients are amongst the sickest in the hospital. Kolic et al. (2015) identified an appropriate clinical response to EWS in only $74.1 \%(n=274)$ of patients, leaving $25.9 \%(n=96)$ receiving an inadequate response. Of even greater concern there was a significantly worsening response in the sickest patients with EWS 5-6 (100\%) and EWS >7 (75\%) ( $p=0.0001)$. Day of the week was also identified to impact on clinical response. Patients admitted at the weekend were more likely to receive an inadequate response than those admitted on a week day $(p=<0.0001)$. A small decrease in clinical response at night was also noted but not statistically significant $(p=0.404)$. This appears to mirror the findings relating to monitoring frequency discussed above. As EWS monitoring is essential for clinical response, weekend compliance is suboptimal in both the afferent and efferent arm. This has significant implications for patient safety out of hours. Ludikhuize et al. (2014) found a delay in clinical response in both the protocolised group $(49 \%)$ and the control group (50\%). Although not statistically significant the delay was clinically concerning at $20 \mathrm{hrs}$ and $44 \mathrm{hrs}$ respectively $(\mathrm{p}=0.79)$. Petersen et al. (2014) identified compliance in the EWS protocol in patients with a score $<2(62 \%)$ and appropriate clinical response to a score $>3(58 \%)$. Of concern, in patients with a high EWS clinical response was worse. 106 events (58\%) where patients with a EWS $>6$ were not treated by a physician and there was no documentation to support the nursing staff has instigated the correct clinical response. In EWS $>9$ only $48 \%$ of patients were managed by a specialist 
team. Again, this mirrors the findings for scoring accuracy and monitoring frequency suggesting the sickest patients are beings managed sub optimally with failures in both the afferent and efferent arm of the EWS protocol. Overall, non-compliance in the EWS protocol was identified in $92 \%$ of cases. Jones et al. (2011) suggests that with the use of electronic EWS clinical response increased from $29 \%$ to $78 \%$ in patients with a EWS of 3,4 or 5 $(p=<0.001)$. This still suggests a failure rate of $22 \%$ which remains suboptimal. Clinical response to a EWS $>5$ was also statistically significant at $96 \%(p=<0.001)$. Although significant improvement is demonstrated with the use of electronic EWS protocols, noncompliance still occurs at all EWS stages.

\section{Discussion of Findings}

In summary, this review demonstrates poor compliance with the EWS protocol. There is significant scoring inaccuracy with omitted EWS, missing elements of the EWS and incorrectly calculated EWS (Odell 2015; Niegsch et al. 2013; Ludikhuize et al. 2014). These errors are compounded in the higher EWS ranges (Kolic et al. 2015). The use of automated EWS can improve scoring accuracy but errors remain (Jones et al. 2011). Adherence to monitoring frequency is poor with a with higher EWS being associated with reduced compliance with the protocol (Petersen et al. 2014). Compliance with EWS may be reduced at a weekend and during night time hours (Hands at el. 2013; Odell 2015). The use of automated systems alone do not improve observation frequency when compared to a manual protocol (Jones et al. 2011). There is also evidence of inadequate compliance with the efferent limb of the EWS (Odell, 2015) with concerning extended delays to clinical review (Ludikhuize et al. 2014). There is evidence of worsening clinical response with increasing EWS (Kolic et al. 2015; Petersen et al. 2014). Although significant improvement is demonstrated in clinical response with the use of electronic EWS protocols, non-compliance still occurs at all EWS stages (Jones et al. 2011).

When considering the findings of this review within the context of the wider literature it is reasonable to suggest that the success of EWS relies on the effectiveness of its implementation. It is unfair to make a judgement on the clinical effectiveness of EWS given the poor implementation. When goals are not achieved there is a tendency to blame the individual rather than looking at the wider context. This study suggests that compliance is poor and we must explore the reasons why. This needs to include issues surrounding culture, professional norms and values, hierarchies and clinical autonomy. 
An improvement in documentation is still required as research suggests that documentation is incomplete is most cases (Ludikhuize et al. 2012). This is particularly important when considering respiratory rate and conscious level both important indicators of critical illness (Alam et al. 2014). With the introduction of an EWS both observation frequency and documentation can be improved (De Meester et al. 2013) but there is still much work to do. Inadequate nursing surveillance has been associated with failure to recognise and respond (Kelly and Vincent 2011). Inadequate staffing and skill mix, poor multi-disciplinary teamwork, poor communication, overuse of technology and lack of family input have all been identified as barriers to effective nursing surveillance (Henneman et al. 2012; Kutney-Lee et al. 2009). The weekend effect has been well documented in other studies with increased mortality prevalent at a weekend (Aylin et al. 2010; Freemantle et al. 2012). Experience and expertise of both nursing and medical staff may be diluted during this time which may influence compliance with EWS. More research into the weekend effect would be useful.

Education is essential to understand the potential benefits of EWS and their relationship to improved clinical outcomes (Alam et al. 2015; Paterson et al. 2006; Subbe et al. 2003; Bokhari et al. 2010). Acute clinical changes are often recognised and acted upon in a timely fashion using automated skills based behaviour or rule based behaviour using pattern recognition. However, deterioration can often be subtle and for a prolonged period. This demands knowledge based behaviour using observation, experience, consultation and cognitive processing. Subjectively the patient's condition may be deteriorating however the objective measurements are not yet severe enough to activate the EWS. In these situations, response to deterioration is often delayed as staff wait for more objective data to become available (Braaten 2015).

Cultural barriers can affect the decision to act on an EWS. Braaten (2015) identifies informal hierarchical norms in the hospital culture as a constraint to recognition and response. The need to justify escalating the management of a deteriorating patient demands confidence in assessing the patient especially in instances of subtle change. Not wanting to instigate a false alarm or to appear incompetent and unable to handle the situation have been identified as barriers to recognition and response (Astroth et al. 2013). This may be accompanied by a fear of reprisal or criticism of the escalation if it is deemed to be unnecessary. This need for justification leads to delays in treatment and worse clinical outcomes. Shearer et al. (2012) identified the most common reason for failure to respond was that the staff involved felt that they had the clinical situation under control despite an elevated EWS. This suggests that a shift in both education and culture is needed to ensure staff fully engage with, accept and value the EWS system. 


\subsection{Methodological limitations of the studies}

All papers included noted that the single centre nature of their studies may limit external validity. Petersen et al. (2014) and Kolic et al. (2015) acknowledged small sample sizes as a limitation which may constrain the generalisability of their results. Several studies acknowledged limitations in their data collection. Niegsch et a.l (2013) reports that during data collection, several wards were closed due to planned ward reallocation and holidays. This led to smaller than expected data set. Odell (2015) reports a considerable number of missing records which resulted in an incompleteness of data for analysis. Ludikhuize et al. (2014) notes that exclusions of measurements when the patients is absent from the ward may have resulted in an underestimation of findings as it is possible that patients may have been receiving an intervention for clinical deterioration during this time. They also acknowledge that, as vital signs were recorded three times daily in the protocolised group may also lead to increased awareness of clinical deterioration. Finally, Jones et al. (2011) argues that it was impossible to control for external factors which may have influenced length of stay. As their study took place at various times of the year, seasonal illness may have contributed to the increased length of stay in the baseline phase.

\subsection{Limitations of the review}

There are limited studies exploring compliance with the EWS protocol which makes it difficult to generalise findings. Whilst the authors cannot guarantee that all papers were identified, the robust search strategy and citation searching should have addressed this issue.

\subsection{Recommendations and implications for practice}

For EWS to be effective, compliance with all aspects of the efferent and afferent limb must take place. There is evidence to suggest that EWS improve patient outcome but compliance with the EWS protocol is poor. Outcomes can only be positively affected if staff complete the EWS in its entirety, calculate the score accurately, monitor in line with the protocol frequency and escalate according to clinical response.

\subsection{Implications for future research}

Despite evidence that EWS is effective in improving patient outcomes, compliance with the EWS protocol is poor. Despite clear EWS protocols staff often fail to follow them and consequently, sub-optimal care of deteriorating ward patients continues (Hogan et al. 2012; NCEPOD, 2012). There remain opportunities to investigate why staff fail to adhere to the EWS protocol including the social, cultural and inter-professional issues that prevent staff for recording vital signs and acting on the results. Few papers exist which explore the reasons for non- compliance using a mixed methods approach (Shearer et al. 2012). This approach 
may allow greater understanding of the barriers to effective use of EWS enabling the development of evidence based implementation strategies.

\section{Conclusion}

Compliance with EWS is poor but the cause is unidentified. Outcomes can only improve if staff complete the EWS fully, calculate the score accurately, monitor according to protocol and escalate according to clinical response. Social, environmental and professional behaviours that affect effective use of track and trigger tools should be explored to improve our understanding of suboptimal management of the deteriorating patient.

\section{References}

ALAM, N., HOBBELINK, E., VAN TIENHOVEN, A., VAN DE VEN, P., JANSMA, E. and NANAYAKKARA, P., 2014. The impact of the use of the early warning score (EWS) on patient outcomes: A systematic review. Resuscitation, 85, pp. 587-594.

ALAM, N., VEGTING, I., HOUBEN, E., VAN BERKEL, B., VAUGHAN, L. and KRAMER, M., 2015. Exploring the performance of the National Early Warning Score (NEWS) in a European emergency department. Resuscitation, 90, pp. 111-115.

ASTROTH, K., 2013. Qualitative exploration of nurses' decisions to activate rapid response teams. Journal of Clinical Nursing, 22(19-20), pp. 2876-1882.

AUDIT COMMISSION, 1999. Critical to Success. London: Audit Commission.

AYLIN, P., YUNUS, A., BOTTLE, A., MAJEED, A. and BELL, D., 2010. Weekend mortality for emergency admissions. A large, multicentre study. Quality \& safety in health care, 19(3), pp. 213-217.

BOKHARI, S., MUNIR, Y., MEMON, S., BYRNE, J., RUSSEL, N. and BEED, M., 2010. Impact of critical care reconfiguration and track and trigger outreach team intervention on outcomes of haemotology patients requiring intensive care admission. Annals of Haemotology, 89, pp. 505-512.

BRAATEN, J., 2015. Hospital Systems Barriers to Rapid Response Team Activation: A Cognitive Work Analysis. American Journal of Nursing, 115(2), pp. 22-32.

CRITICAL APPRAISAL SKILLS PROGRAMME (CASP), 2014-last update, CASP Checklists [Homepage of Oxford. CASP], [Online]. Available: http://www.casp-uk.net/ [02/07/2018, 2015].

DE MEESTER, K., HAEGDORENS, F., MONSIEURS, K., VERPOOTEN, G., HOLVOET, A. and VAN BOGAERT, P., 2013. Sis day postoperative impact of a standardised nurse 
observation and escalation protocol: A preintervention and postintervention study. Journal of Critical Care, 28, pp. 1068-1074.

DEPARTMENT OF HEALTH, 2000a. Comprehensive Critical Care: A Review of Adult Critical Care Services. London: The Stationary Office.

FERRARI, R., 2015. Writing narrative style literature reviews. Medical Writing, 24(4), pp. 230-235.

FRANKLIN, C. and MATHEW, J., 1994. Developing strategies to prevent in-hospital cardiac arrest: analysing responses of physicians and nurses in the hours before the event Critical Care Medicine, 22, pp. 244-247.

FREEMANTLE, N., RICHARDSON, M., WOOD, J., RAY, D., KHOSLA, S., SHAHIAN, D., ROCHE, W., STEPHENS, I., KEOGH, B. and PAGANO, D., 2012. Weekend hospitalization and additional risk of death: an analysis of inpatient data. Journal of the Royal Society of Medicine, 105(2), pp. 74-84.

GARRARD C, Y.J., 1998. Sub-optimal care of patients before admission to intensive care British Medical Journal, 316, pp. 1841-1842.

GOLDHILL, D., WORTHINGTON, L., MULCAHY, A., TAHLING, M. and SUMNER, A., 1999. The patient at risk team: identifying and managing seriously ill patients. Anaesthesia, 54, pp. 853-860.

HANDS, C., REID, E., MEREDITH, P., SMITH, G.B., PRYTHERCH, D.R., SCHMIDT, P.E. and FEATHERSTONE, P.I., 2013. Patterns in the recording of vital signs and early warning scores: compliance with a clinical escalation protocol. BMJ quality \& safety, 22(9), pp. 719726.

HENNEMAN, E., 2012. Surveillance: a strategy for improving patient safety in acute and critical care units. Critical Care Nursing, 32(2), pp. e9-e18.

HIGGINS, J.P.T. and GREEN, S., 2011. Cochrane Handbook of Systematic Reviews, Version 5.1.0. Cochrane Collaboration. http://www.cochrane.org/handbook edn.

HOGAN, H., HEALEY, F., NEALE, G., THOMSON, R., VINCENT, C. and BLACK, N., 2012. Preventable deaths due to problems in care in English acute hospitals: a retrospective case record review study http://qualitysafety.bmj.com edn.

INTENSIVE CARE NATIONAL AUDIT RESEARCH CENTRE CASE MIX PROGRAMME DATASET SPECIFICATION, 2012-last update, National Cardiac Arrest Audit (NCAA) . Available: https://www.icnarc.org/Default.aspx.

JONES, S., MULLALLY, M., INGLEBY, S., BUIST, M., BAILEY, M. and EDDLESTON, J.M., 2011. Bedside electronic capture of clinical observations and automated clinical alerts to improve compliance with an Early Warning Score protocol. Critical Care and Resuscitation, 13(2), pp. 83.

KOLIC, I., CRANE, S., MCCARTNEY, S., PERKINS, Z. and TAYLOR, A., 2015. Factors affecting response to national early warning score (NEWS). Resuscitation, 90, pp. 85-90. 
KUTNEY-LEE, A., 2009. Development of the hospital surveillance capacity profile. Research Nurse Health, 32(2), pp. 217-228.

LUDIKHUIZE, J., BORGERT, M., BINNEKADE, J., SUBBE, C., DONGELMANS, D. and GOOSSENS, A., 2014. Standardised measurement of a modified early warning score results in enhanced implementation of a rapid response system: A quasi-experimental study. Resuscitation, 85, pp. 676-682.

LUDIKHUIZE, J., SMORENBURG, S. and DE ROOIJ, S., 2012. Identification of deteriorating patients on general wards: measurement of vital parameters and potential effectiveness of the Modified Early Warning Score. Journal of Critical Care, 27, pp. 424-513.

MCGLOIN, H., ADAMS, S. and SINGER, M., 1999. Unexpected deaths and referrals to critical care of patients on general wards. Are some cases potentially avoidable? Journal of the Royal College of Physicians, 33, pp. 255-259.

MCQUILlAN, P., PILKINGTON, F., ALLAN, A., TAYLOR, B., SHORT, A., MORGAN, G., NEILSON, M. and SMITH, G., 1998. Confidential enquiry into quality of care before admission to intensive care British Medical Journal, 316, pp. 1853-1858.

MENDELEZ-TORRES, GJ., O'MARA-EVES J., BRUNTON G., CAIRD G., PETTICREW M., 2016. Interpretive analysis of 85 systematic reviews suggests that narrative syntheses and meta-analyses are incommensurate in argumentation Research Synthesis Methods 8(1) pp. $109-118$

MILES, M. and HUBERMAN, A., 1994. Qualitative Data Analysis. 2 edn. Thousand Oaks, California: Sage Publications.

MOHER, D., SHAMSEER, L., CLARKE, M., GHERSI, D., LIBERATI, A., PETTICREW, M., SHEKELLE, P. and STEWART, L.A.P.G., 2015. Preferred reporting items for systematic review and meta-analysis protocols (PRISMA-P) 2015 statement. Systematic Reviews, 4(1),.

NATIONAL CONFIDENTIAL ENQUIRY INTO PATIENT OUTCOME AND DEATH. 2015. Just Say Sepsis! A review of the process of care recieved by patients with sepsis. London: NCEPOD.

NATIONAL CONFIDENTIAL ENQUIRY INTO PATIENT OUTCOME AND DEATH. 2012. Cardiac Arrest Procedures: Time to Intervene? London: NCEPOD

NIEGSCH, M., FABRITIUS, M.L. and ANHØJ, J., 2013. Imperfect implementation of an early warning scoring system in a Danish teaching hospital: a cross-sectional study. PloS one, 8(7), pp. e70068.

O'CONNOR, D., GREEN, S. and HIGGINS, J., 2008. Defining the review question and developing criterial for including studies. In: J. HIGGINS and S. GREEN, eds, Cochrane Handbook for Systematic Reviews and Interventions. Chichester: Wiley, .

ODELL, M., 2015. Detection and management of the deteriorating ward patient: an evaluation of nursing practice. Journal of Clinical Nursing, 24(1-2), pp. 173-182. 
PATERSON, R., MACLEOD, D., THETFORD, D. and ET AL., 2006. Prediction of in-hospital mortality and length of stay using an early warning scoring system: clinical audit. Clinical Medicine, 6, pp. 281-284.

PETERSEN, J.A., MACKEL, R., ANTONSEN, K. and RASMUSSEN, L.S., 2014. Serious adverse events in a hospital using early warning score-What went wrong? Resuscitation, 85(12), pp. 1699-1703.

RESUSCITATION COUNCIL (UK)., 2010. Advanced Life Support. 6 edn. London: Resuscitation Council (UK).

SHEARER, B., MARSHALL, S., BUIST, M., FINNIGAN, F., KITTO, S., HORE, T., STURGESS, T., WILSON, S. and RAMSEY, W., 2012. What stops hospital clinical staff from following protocols? An analysis of the incidence and factors behind the failure of bedside clinical staff to activate the rapid response system in a multi-campus Australian metropolitan healthcare system. BMJ Quality and Safety, 21, pp. 569-575.

SMITH, G., 2006. Hospital-wide physiological surveillance - A new approach to the early identification and management of the sick patient. Resuscitation, 17, pp. 19-28.

SUBBE, C., DAVIES, R., WILLIAMS, E., RUTHERFORD, P. and GEMMELL, L., 2003. Effect of introducing the modified early warning score on clinical outcomes, cardio-pulmonary arrests and intensive care utilisation in acute medical admissions. Anaesthesia, 58, pp. 775803.

THE CENTRE FOR REVIEWS AND DISSEMINATION., 2014, 2014-last update, PROSPERO. [Homepage of The Centre for Reviews and Dissemination.], [Online]. Available: http://www.crd.york.ac.uk/PROSPERO/ [02/15/2016, 2016].

WELSH, J., 2000. Using assessment to identify and prevent critical illness Nursing Times, 96(20), pp. 3-4. 
